Original Research Article

\title{
The Application of Flipped Classroom in Preventive Medicine Teach- ing
}

Kangyong Liao*

Shanghai Gaoxin Huabo Hospital. E-mail: liaoky@163.com

Abstract: The teaching content of preventive medicine courses in secondary vocational schools is too much, but the class hours are few. So students generally have little interest, which affects the teaching effect. This article focuses on the current problems in preventive medicine teaching in secondary vocational schools, analyzes the advantages of flipped classrooms, and discusses the issues that should be considered when flipped classrooms are applied.

Keywords: Flipped Classrooms; Preventive Medicine; Teaching

Although traditional classroom teaching is indispensable for students to master knowledge, it's obviously not enough to cultivate students' abilities of independent learning, innovative thinking, and analyzing and solving problems. Flipped classroom is a form of teaching in which lectures and other traditional classroom elements are moved outside the classroom, and replaced by more student interaction and group discussion. Flipped classroom can greatly improve students' enthusiasm for learning and put them in a proactive learning state in the classroom. This is useful for cultivating students' teamwork skills, providing students with personal guidance, and cultivating students' self-learning ability, innovative thinking ability, and analytical problem-solving ability. Preventive medicine is an important course for many medical students. It is of great significance to the cultivation of medical students' necessary medical knowledge and quality. The content of preventive medicine courses contains more difficult knowledge points and moderately difficult points which are suitable for students to do self-study discussions and more suitable for flipped classroom teaching ${ }^{[1]}$. Starting from the flipped class- room teaching of preventive medicine, this article discusses the implementation steps, implementation evaluation, and teaching resource preparation to provide references for the application of flipped classrooms in more medical courses. Therefore, the development of the subject has significant practical and theoretical value.

\section{The concept of flipped classroom}

"Flipped classroom" is to reverse the order of classroom teaching, using the model of "teaching after learning”. In the electronic information environment, teachers provide teaching micro-videos on the online teaching platform, and ask students to complete teaching tasks such as watching teaching videos, materials and finishing online tests after class, and learn knowledge and skills before class. The classroom becomes a platform for interactive communication between teachers and students where they conduct face-to-face discussions. And then teachers conduct after-class teaching evaluations. In the teaching process, teachers play an important role as a participant and guider, and during which students are more proactive ${ }^{[1]}$. 


\section{The status quo of preventive medicine course teaching in sec- ondary vocational schools}

\subsection{Students pay more attention to clinical practice than prevention}

Most students in secondary vocational health schools do not pay much attention to preventive medicine courses. They generally believe that preventive medicine knowledge is useless for future medical and nursing jobs. Students lack the motivation to learn, and study and examinations are only to meet the teaching requirements of schools.

\subsection{Less class hours, wide range of courses}

In medical education, preventive medicine has not been placed in its proper place. Students in secondary vocational schools have less time to study at school and heavy learning tasks. Therefore, when arranging teaching content, they emphasize clinical majors and neglect preventive medicine, so that preventive medicine teaching hours are less, teaching facilities are not equipped well, and many practical contents cannot be developed, which makes it difficult to improve students' overall quality. The preventive medicine courses have a wide range of contents, including preventive health care, nutrition and food hygiene, health statistics, and epidemiology, which are more complicated and difficult to understand and remember. In the case of having few school hours, teaching often can only be done in one area, so it is difficult to highlight the key points, and it is impossible for students to study in depth, which affects the teaching effect of preventive medicine courses.

\subsection{Backward teaching methods}

At present, the teaching of preventive medicine courses in secondary vocational schools is still based on lectures. Although multimedia teaching is used, teachers still use the traditional mode of duck-filling explanations. Most of the lectures in the classroom are about the content of textbooks, and students are in passive status. In addition, most of the preventive medicine experimental classes cannot be carried out due to time and conditions. It is difficult to arrange students to visit communities, disease control departments, and other industrial enterprises. As a result, students cannot associate theoretical knowledge with practical work. This indoctrination method not only fails to fully mobilize students' enthusiasm, but also makes teachers feel distressed.

\subsection{Lack of teachers}

Except for rural medicine, preventive medicine is not a professional course in majors like nursing and pharmacy at secondary vocational schools. Schools do not pay enough attention to preventive medicine courses. In addition, preventive medicine teaching conditions and resources are poor, and the development space for professional teachers is limited, which has led to relative lack of teachers of preventive medicine major in many schools.

\section{Advantages of flipped classroom in the teaching of preventive medi- cine in secondary vocational schools}

\subsection{Effectively solve the problem of large scale of content of preventive medicine courses with few hours}

In the flipped classroom, unlimited repeated learning is a great convenience for students, which greatly solves the problem of large scale of content of preventive medicine courses with few hours. For example, contents in the part of health statistics are of abstract concept, strong logic and a large number of calculation formulas. They have always been explained with limited time in class, causing students to understand and master very little. Through the flipped classroom teaching method, students can watch instructional videos repeatedly and do unlimited online practice according to their own situations and the level of knowledge mastery until they really master. The flipped classroom teaching method makes the content of the preventive medicine classroom with complex knowledge permanently archived, which can be used for review or supplementary lessons, so that every student can get personalized education ${ }^{[2]}$.

\subsection{Improve students' learning enthusiasm and initiative, and improve preventive medi- cine teaching effects}

Through flipped classroom, students watch instructional videos in their favorite way in their spare time, which is a kind of autonomous learning in the true sense. Students can study in a relaxed atmosphere without hav- 
ing to strain their nerves and worry about missing something. The pace of learning is all up to students themselves. If they understand the content, they can fast forward. If they don't understand it, they can rewind and watch repeatedly. They can also stop to think or take notes and can have real-time discussions and interactions with other students on the Internet, and ask for help. In addition, they can also check information whenever they need it. By learning before class, every student enters the class with questions to seek answers, and they become the main body of learning in the class. For example, the teaching of nutrition emphasizes both theory and practice, but there are many knowledge points, and there are big weaknesses in the traditional teaching mode, which cannot really attract students' interest. After the introduction of flipped classrooms, vivid teaching videos are used to make students learn the basic theoretical knowledge of nutrition independently before class. In the classroom, teachers use life situations or cases as guidance to allow students to carry out various activities such as discussion, so that theories can be transformed into practice, which greatly stimulates students' interest in learning and improves the quality and effectiveness of preventive medicine courses ${ }^{[3]}$.

\subsection{Better display the ability of preventive medicine teachers, which is conducive to the self-development of teachers}

For professional teachers, flipped classrooms put forward higher requirements. Teachers must not only have a high sense of responsibility, good teaching ability, rich professional knowledge of prevention, familiar with teaching materials, teaching goals, and key teaching difficulties, but also have the ability to use modern information technology, such as computer technology, multimedia technology, and network technology. Only by realizing the integration of professional knowledge skills and related knowledge, and giving full play to the spirit of teamwork, can teachers produce good teaching videos. Flipped classroom can also promote teachers to continuously improve in-depth classroom research and classroom organization ability. In the communication and interaction between teachers and students, they constantly reflect and summarize, so as to continuously produce new ideas for preventive medicine teaching reform.

\subsection{Cultivate students' sense of teamwork}

In the flipped classroom, the students in a dormitory of the class are used as a study group, which not only facilitates the students' extracurricular group discussion, but also stimulates the improvement of students' team consciousness and the strengthening of the spirit of cooperation. For the sake of their collective honor, some group members work together to search for documents and materials; each performs its own duties, and finally concentrates collective wisdom, and jointly produces report on learning results. The friendship between students is also cultivated in the process of learning and discussing. Flipped classroom increases the opportunities for teacher-student communication, improves the ability of teamwork, promotes students' good performance in the group, makes students responsible for their own learning, and truly achieves mutual benefit in teaching and mutual assistance.

\subsection{Cultivate students' communication skills}

In the flipped classroom teaching of preventive medicine, there is a link to report group learning achievements in the classroom. Every time each group finishes the class report, they will change different group members. In this way, the group learning achievement report becomes an important link for each group member to show their self-image and win glory for the group. In order to make the report vivid, the members actively prepare before class. The meticulous rehearsal and the design of some infectious links and languages are praised by classmates, inspiring more students to show themselves in public situations and improve their language expression skills.

\section{Application of flipped classroom in preventive medicine teaching in secondary vocational schools}

\subsection{Build a preventive medicine mi- cro-course system with the support of the school}

Micro-video and network platforms are the prerequisite and important foundation for implementing flipped classrooms. To apply flipped classrooms in preventive medicine teaching in secondary vocational schools, schools need to provide strong support. 
First, it is necessary to obtain the school's attention to preventive medicine courses, form a sense of goal of cultivating new preventive healthcare medical talents, improve preventive medicine teaching conditions and teaching resources, and enrich and expand the professional teaching team. Schools should provide financial support, organize preventive medicine professional teachers, computer teachers, technical management personnel and other talents, establish a preventive medicine micro-course production team, and independently develop and produce preventive medicine micro-videos suitable for secondary vocational students. Under sufficient funds, they can also purchase high-quality micro-courses on the Internet, develop and upgrade them, and gradually build a preventive medicine micro-course resource library.

\subsection{Optimize the teaching design of mi- cro-course}

Flipped classroom uses micro-course as the carrier. To turn the shriveled and lifeless medical knowledge into flesh-and-blood, lifelike teaching activities, it requires optimization of teaching design, including the design of teaching videos before class, the design of classroom activities and the design of curriculum evaluation. In the design of teaching videos, it should be noted that flipped classrooms are not suitable for all teaching content of preventive medicine. Some difficult parts can be selected, such as statistics, or the nutrition part with scattered knowledge points and a wide range of topics. The teaching content should be analyzed and refined according to the teaching materials and teaching objectives, and the content should be focused and refined. In the design of classroom activities, there must be diversified and rich activities, such as case discussion, role playing, and group debate. Finally, the evaluation of the course should be combined with the flipped classroom model to design an evaluation system for the whole process before, during and after class, which fully reflects the comprehensive performance of students in knowledge acquisition, ability training, and collaborative communication.

\section{Conclusion}

In summary, the advantages of flipped classrooms to improve students' self-learning ability, comprehensive analysis ability, teamwork, and communication skills have been recognized by more and more educators. Although flipped classrooms still have shortcomings, they believe that through practice and exploration of educators, the flipped classroom will surely be more mature and perfect, and become one of the important ways for China to cultivate innovative medical talents.

\section{References}

1. Sang J. Application of flipped classroom in preventive medicine teaching (in Chinese). Health for Everyone 2020; 513(4): 83.

2. Yan Y. Application of flipped classroom in preventive medicine teaching in secondary vocational schools (in Chinese). Journal of Juamjusi Education Institute 2019; (11): 105, 107.

3. $\mathrm{Xu} \mathrm{Q}$. Exploration of multi-discipline integrated flipped classroom in preventive medicine course teaching (in Chinese). Think Tank Era 2019. 